\title{
Research of Quality Standards for Stachydrine Hydrochloride in Chinese Medicine TJF Granule
}

\author{
Yao Lu ${ }^{1}$, Wei Yu$^{2}$, Pingniang Shen ${ }^{2}$, T. J. Khoo ${ }^{1}$, C. Wiart ${ }^{1}$ \\ ${ }^{1}$ Faculty of Sciences, School of Biomedical Sciences, University of Nottingham(Malaysia Campus), Semenyih, Malaysia; ${ }^{2}$ National \\ Engineering Research Center for Traditional Chinese Medicine, Shanghai, China. \\ Email: khyx2lyo@nottingham.edu.my
}

Received March 18 ${ }^{\text {th }}, 2013$; revised May $4^{\text {th }}, 2013$; accepted May $14^{\text {th }}, 2013$

Copyright (C) 2013 Yao Lu et al. This is an open access article distributed under the Creative Commons Attribution License, which permits unrestricted use, distribution, and reproduction in any medium, provided the original work is properly cited.

\begin{abstract}
A high-performance liquid chromatographic method was applied to the determination of stachydrine hydrochloride concentration in TJF granule (Chinese name: Tiao-Jing-Fang), using a mobile phase of methanol-acetonitrile (50:50, $\mathrm{v} / \mathrm{v})$ by the Agilent Kro-masi $\mathrm{NH}_{2}$ column $(250 \mathrm{~mm} \times 4.6 \mathrm{~mm}, 5 \mu \mathrm{m}, \mathrm{S} / \mathrm{N}: 22 \mathrm{~N} 25110)$. Detection wavelength was 201 $\mathrm{nm}$. The result revealed good linearity of stachydrine hydrochloride and was obtained within the range of $0.20-1.98$ $\mu \mathrm{g} / \mathrm{mL}(\mathrm{R}=0.9995)$. The average recovery was $97.01 \%$; the relative standard deviation (RSD) was $0.19 \%$. To the best of our knowledge, this is the first report dedicated to the determination of stachydrine hydrochloride by the evaporative light scattering detector-high-performance liquid chromatographic (ELSD-HPLC) method.
\end{abstract}

Keywords: TJF Granule; Quality Standards; Traditional Chinese Medicine; Evaporative Light Scattering Detector (ELSD); High-Performance Liquid Chromatographic (HPLC) Method; Stachydrine Hydrochloride; Pharmaceutical Analysis; Determination

\section{Introduction}

Stachydrine Hydrochloride (Figure 1) is one of the major active constituent of Herba Leonuri (Chinese herbal name: Yi-Mu-Cao) [1]. The crude extract of Herba Leonuri has been used in traditional Chinese medicine to treat irregular menses and other gynecologic diseases [2-9].

Since any natural product considered for its therapeutic value must be evaluated for consistency, a proper identification of the herbal ingredients in each preparation or medical product is an obvious requirement. Concentrated pharmaceutical herbal products and the decoction herbal products have been widely adopted for clinical use in most Asian countries like: China, Malaysia, Mongolia, Japan, Korea, and even in certain countries of the whole world.

Herbal products offer an alternative to Western medicines and are often considered to be non-toxic by the general public. A major criticism of herbal products is that they fail to meet modern quality assurance standards established for conventional medicines. Thus, quantitative determination of the active or marker components in medicinal herbs is a compulsory element for quality con- trol. Several high-performance liquid chromatographic (HPLC) methods have been developed for the determination of stachydrine hydrochloride in herbs using silica columns $[10,12]$ or reversed-phase C18 columns [11,12]. The aim of this current study is to develop a simple, reliable routine analytical method for the quality control of herbal medicine preparations by determining the stachydrine hydrochloride concentration in Herba Leonuri, and a traditional herbal preparation named TJF (Chinese name: Tiao-Jing-Fang) granule.

\section{Experimental}

\subsection{Chemicals \& Reagents}

Stachydrine hydrochloride standard substance (The National Institute for Food and Drug Control, batch number: 110712-200709), TJF Granule (batch number: 091201, 091202, 091203), methanol (Merck, chromatographically pure), acetonitrile (ACN) (Merck, chromatographically pure), ultrapure water (UPW), ethanol (Merck, analytically pure (AR)), N-butanol (Merck, analytically pure (AR)), hydrochloric acid ( $\mathrm{HCl}$ (Merck, analytically pure (AR)), bismuth subnitrate (Merck, analytically pure (AR)), glacial acetic acid (Merck, analytically pure (AR)), 


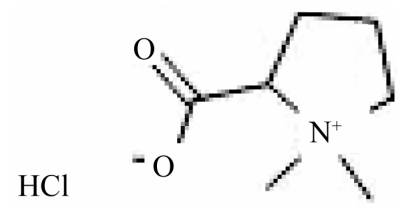

Figure 1. Chemical structure of stachydrine hydrochloride.

potassium iodide (Merck, analytically pure (AR)).

The traditional Chinese herbal preparation TJF Granule containing: Herba Leonuri (18 g), Rhizoma Chuanxiong (9 g), Rhizoma Cyperi (9 g), Semen Vaccariae (9 g), Caulis Spatholobi (9 g), and Fructus Lipuidambaris (9 g) was kindly provided by Dr. Wang Ling Tai from Shanghai Shu Guang Hospital.

\subsection{Chromatography}

Agilent 1100 High Performance Liquid Chromatograph (HPLC), includes: Alltech 2000 Evaporative Light Scattering Detector (ELSD), Agilent 1100 ChemStation, Alltech 1100 Full Wavelength Ultraviolet (UV) Detector, Agilent 1100 Online Vacuum Degasser, Agilent 1100 manual injector; Agilent Kro-masi $\mathrm{NH}_{2}$ column $(250 \mathrm{~mm}$ $\times 4.6 \mathrm{~mm}, 5 \mu \mathrm{m}, \mathrm{S} / \mathrm{N}: 22 \mathrm{~N} 25110$ ); Si mplicity Superpure Water System (Milipore); Analytical Balance (METTLER XS105); $50 \mu$ Microsyringe (Hamilton).

The mobile phase consisted of methanol-acetonitrile $(50: 50, \mathrm{v} / \mathrm{v})$, its flow-rate was $1 \mathrm{ml} / \mathrm{min}$. The mobile phase was filtered through a Millipore $0.45 \mu \mathrm{m}$ filter and degassed prior to use. The detection wavelength was set at $201 \mathrm{~nm}$.

\subsection{Method Validation and Result}

\subsubsection{Herba Leonuri Identification by TLC}

Preparation of reference solution: To get stachydrine hydrochloride standard substance, add ethanol and make a solution into the concentration of $2 \mathrm{mg} / 1 \mathrm{~mL}$.

Preparation of TJF Granule sample solution: To get 6 g TJF Granule, add ethanol $30 \mathrm{~mL}$, extracted 60 minutes twice by hot reflux extraction method, filters and combine the filtrate, concentrates evaporation to dryness, dissolves the residue in $0.5 \mathrm{~mL}$ ethanol for analysis by TLC as TJF Granule sample solution.

Preparation of negative control product solution: To get $6 \mathrm{~g}$ Negative control product granule (TJF Granule without Herba Leonuri), add ethanol $30 \mathrm{~mL}$, extracted 60 minutes twice by hot reflux extraction method, filters and combine the filtrate, concentrates evaporation to dryness, dissolves the residue in $0.5 \mathrm{~mL}$ ethanol for analysis by TLC as negative control product solution.

Preparation of chromogenic agent (diluted iodized bismuth potassium solution): To get $0.85 \mathrm{~g}$ Bismuth subnitrate, adds $10 \mathrm{ml}$ glacial acetic acid and dissolves into $40 \mathrm{ml}$ Distilled water - that is the former solution. Take 5 $\mathrm{ml}$ former solution before use, add $5 \mathrm{ml}$ potassium iodide solution $(4 \rightarrow 10)$ and $20 \mathrm{ml}$ glacial acetic acid, dilute into $100 \mathrm{ml}$ solution by Distilled water. (China Pharmacopoeia Committee, 2005).

According to the thin-layer chromatography (TLC) test in appendix VIB of the first section of Chinese Pharmacopoeia 2005 Edition, accurate absorb $20 \mu \mathrm{L}$ negative reference substance solution and TJF Granule sample solution respectively, respectively point in the same silica gel plate, developing with the developing solvent N-butanol-Hydrochloric acid-Distilled water (4:1:0.5), developing distance is about $8 \mathrm{~cm}$, remove and dry, spraying with the test solution of diluted iodized bismuth potassium solution, heating in $105^{\circ} \mathrm{C}$ until characteristic spots appear clearly.

Result: In the identification test there's the same colour speck in the preparation Chromatography while there's no the same colour speck in the control sample. The result is shown in Figure 2.

Developing solvent: N-butanol-Hydrochloric acidDistilled water (4:1:0.5).

Chromogenic agent: Diluted iodized bismuth potassium solution.

1) Negative control product solution (TJF Granule without Herba Leonuri);

2) Stachydrine hydrochloride standard substance;

3)-5) TJF Granule sample (batch number: 091201, 091202, 091203).

\subsubsection{Determination of Stachydrine Hydrochloride by HPLC}

1) Chromatography condition and System suitability test

The determination was performed by ELSD-HPLC, Agilent Kro-masi $\mathrm{NH}_{2}$ column $(250 \mathrm{~mm} \times 4.6 \mathrm{~mm}, 5 \mu \mathrm{m}$, $\mathrm{S} / \mathrm{N}: 22 \mathrm{~N} 25110$ ) was used with methanol-acetonitrile (50:50) as mobile phase. Detection wavelength was 201 $\mathrm{nm}$.

Number of theoretical plates calculated by chromatographic peak of stachydrine hydrochloride would be no

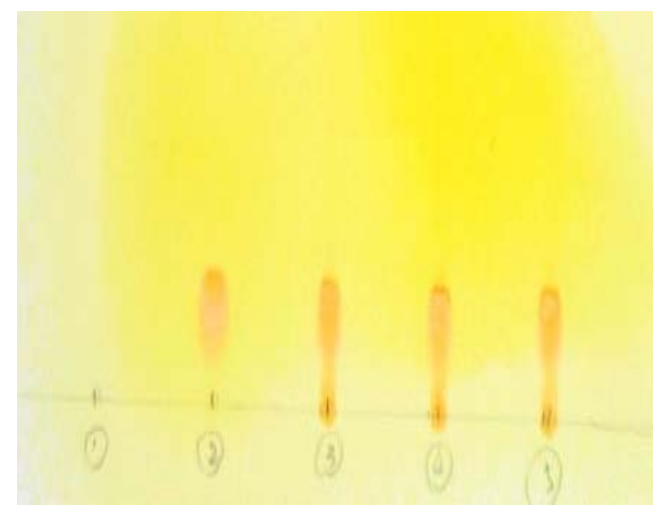

Figure 2. Identification of Herba Leonuri. 
less than 2000.

2) Solution Preparation

Preparation of reference solution: To get moderate Stachydrine hydrochloride standard substance (The National Institute for Food and Drug Control, batch number: $110712-200709$ ), weighting accurately, dry in $105^{\circ} \mathrm{C}$ for 3 hours, weighting accurately, add ethanol to make a solution with a concentration of $0.2 \mathrm{mg} / 1 \mathrm{~mL}$.

Preparation of sample solution: to get TJF Granule $3 \mathrm{~g}$, weighting accurately, adding ethanol $30 \mathrm{~mL}$, heating to reflux for 2 times, I hour for each time, filtering after being cooled, merging of filtrates, concentrating the mixed filtrate to a moderate amount, adding ethanol to dissolve, moving into a $5 \mathrm{ml}$ volumetric flask, dilute with ethanol to volume, and mix, filter, take the subsequent filtrate as the sample solution.

Preparation of negative control product solution: To weight all the ingredients of TJF Granule except the Herba Leonuri, preparing the negative reference substance solution by the same way of TJF Granule sample solution preparation.

3) Determination method

Respectively accurate absorb reference substance solution $10 \mu \mathrm{L}, 20 \mu \mathrm{L}$; TJF Granule sample solution $10 \mu \mathrm{L}$; and negative reference substance solution $10 \mu \mathrm{L}$; inject into the high performance liquid chromatograph according to the chromatographic condition which above-mentioned and test.

4) Linear relationship inspection

To get moderate stachydrine hydrochloride standard substance (The National Institute for Food and Drug Control, batch number: 110712-200709), weighting accurately, adding ethanol to make a solution with concentration of $0.2 \mathrm{mg} / \mathrm{mL}$. Respectively accurate absorb above-mentioned solution $1000 \mu \mathrm{L}, 500 \mu \mathrm{L}, 125 \mu \mathrm{L}, 63$ $\mu \mathrm{L}$ and $32 \mu \mathrm{L}$, move them into $5 \mathrm{~mL}$ volumetric flasks respectively, dilute with ethanol to volume and mix, prepare these solutions as the series of standard substance solutions.

Series of standard substance solutions are injected respectively, and analysis according to the chromatographic condition based on the "Determination of Stachydrine Hydrochloride by HPLC" item, record peak area, calculate regressively through sample concentration $(\mu \mathrm{g} / \mathrm{mL})$ as the abscissa, and logarithm of peak area as the ordinate. Result displays a good linear relation is shown within the detection range of stachydrine hydrochloride. Linear equation is: $\mathrm{y}=0.041 \mathrm{x}+2.882, \mathrm{R}=$ 0.9995 ; linear range is: $0.20-1.98 \mu \mathrm{g} / \mathrm{mL}$. Since the standard curve is not pass the origin, external standard dual point method is adopted to determinate the content of Stachydrine hydrochloride standard substance in products. The result is shown in Figure 3 and Table 1.

5) Accuracy test

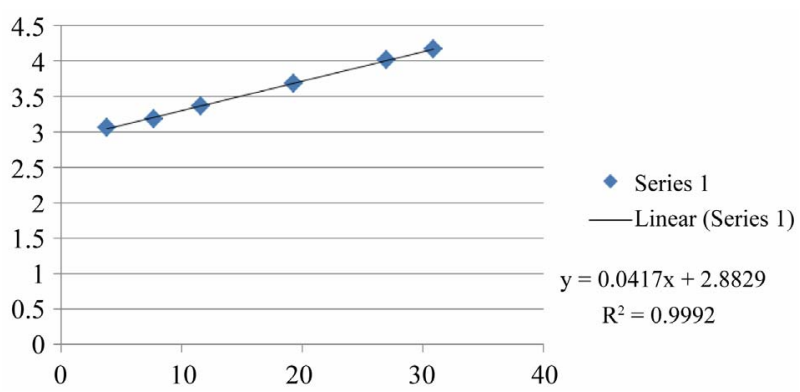

Figure 3. Standard curve of stachydrine hhydrochloride.

Table 1. Linear relation result of stachydrine hydrochloride.

\begin{tabular}{cccc}
\hline $\begin{array}{c}\text { Sample } \\
\text { Concentration } \\
(\mu \mathrm{g} / \mathrm{mL})\end{array}$ & $\begin{array}{c}\text { Integral Value } \\
\text { of Peak Area }\end{array}$ & $\begin{array}{c}\text { Logarithm of } \\
\text { Integral Value of } \\
\text { Peak Area }\end{array}$ & Standard Curve \\
\hline 3.86 & 1153 & 3.0618 & \\
7.72 & 1526 & 3.1836 & \\
11.58 & 2324 & 3.3662 & $\mathrm{y}=0.041 \mathrm{x}+2.882$ \\
19.3 & 4818 & 3.6829 & $\mathrm{R}=0.9995$ \\
27.02 & 10,321 & 4.0137 & \\
30.88 & 14,772 & 4.1694 & \\
\hline
\end{tabular}

Reference substance solution has been absorbed accurately, solutions are injected 5 times continuously. The intra-day coefficient of variation $(\mathrm{CV})$ is calculated by testing the relative standard deviation (RSD) for each chromatographic peak's logarithm of peak area $(\lg \mathrm{A})$. The result is shown in Table 2.

6) Stability Test

To get TJF Granule sample solution from same batch number, solutions are injected in 0 hour, 2 hours, 4 hours, 6 hours, 8 hours, 12 hours and 24 hours respectively. Test result shows that TJF Granule sample solution is stable within 24 hours. The result is shown in Table 3.

7) Repeatability Test

TJF Granule has been weighted accurately, preparing the sample solution by the same way of TJF Granule sample solution preparation to test the repeatability of determination method. RSD is $0.66 \%$, which shows a good repeatability. The result is shown in Table 4.

8) Recovery Test

To get $0.5 \mathrm{~g}$ TJF Granule which content has been calculated as a sample, weighting 9 samples; accurately absorb moderate reference substance solution; preparing the sample solution by the same way of TJF Granule sample solution preparation; calculate the recovery of Stachydrine hydrochloride. The result is shown in Table 5.

9) TJF Granule Determination

To get TJF Granule $5 \mathrm{~g}$, weighting accurately, adding ethanol $40 \mathrm{~mL}$, heating to reflux for 2 times, 1 hour for each time, filtering after being cooled, merging of 
Table 2. The result of accuracy test.

\begin{tabular}{cccc}
\hline Times & Peak Area (A) & Logarithm of Peak Area (lgA) & RSD (\%) \\
\hline 1 & 2911 & 3.4640 \\
2 & 2796 & 3.4465 \\
3 & 2876 & 3.4588 & 0.19 \\
4 & 2829 & 3.4516 & \\
5 & 2857 & 3.4559 & \\
\hline
\end{tabular}

Table 3. The result of stability test.

\begin{tabular}{|c|c|c|c|}
\hline Time (h) & Peak Area (A) & Logarithm of Peak Area $(\lg \mathrm{A})$ & $\operatorname{RSD}(\%)$ \\
\hline 0 & 25,607 & 4.4084 & \\
\hline 2 & 24,939 & 4.3969 & \\
\hline 4 & 25,553 & 4.4074 & \\
\hline 6 & 25,778 & 4.4112 & 0.52 \\
\hline 8 & 25,290 & 4.4029 & \\
\hline 12 & 25,631 & 4.4088 & \\
\hline 24 & 20,718 & 4.3163 & \\
\hline
\end{tabular}

Table 4. The result of repeatability test.

\begin{tabular}{|c|c|c|c|c|c|}
\hline No. & Sample Weight (g) & Peak Area (A) & Logarithm of Peak Area (lgA) & $\mathrm{mg} / \mathrm{g}$ Granule & RSD (\%) \\
\hline 1 & 5.9776 & 25,607 & 4.4084 & 0.2740 & \multirow{6}{*}{0.66} \\
\hline 2 & 5.9983 & 24,939 & 4.3969 & 0.2700 & \\
\hline 3 & 5.9991 & 25,553 & 4.4074 & 0.2728 & \\
\hline 4 & 5.9754 & 25,778 & 4.4112 & 0.2749 & \\
\hline 5 & 5.9982 & 25,290 & 4.4029 & 0.2716 & \\
\hline 6 & 5.9881 & 25,631 & 4.4088 & 0.2737 & \\
\hline
\end{tabular}

Table 5. The result of recovery test.

\begin{tabular}{cccccc}
\hline No. & $\begin{array}{c}\text { Sample Weight } \\
(\mathrm{g})\end{array}$ & $\begin{array}{c}\text { Additional Quantity of Reference } \\
\text { Substance Solution }(\mathrm{mg})\end{array}$ & $\begin{array}{c}\text { Measured Quantity of Stachydrine } \\
\text { Hydrochloride (mg) }\end{array}$ & $\begin{array}{c}\text { Recovery (\%) } \\
\text { Recovery (\%) }\end{array}$ & $\begin{array}{c}\text { RSD } \\
(\%)\end{array}$ \\
\hline 1 & 0.5992 & 0.5 & 0.1050 & 96.29 \\
2 & 0.5636 & 0.5 & 0.1010 & 97.71 \\
3 & 0.4967 & 0.5 & 0.09165 & 94.61 \\
4 & 0.4679 & 0.4 & 0.06585 & 95.30 & 97.01 \\
5 & 0.4987 & 0.4 & 0.06956 & 98.45 & 0.75 \\
6 & 0.5078 & 0.4 & 0.07061 & 99.15 & 95.40 \\
7 & 0.3891 & 0.2 & 0.02423 & 99.66 & 96.54 \\
8 & 0.4488 & 0.2 & 0.02742 & 0.02724 & \\
9
\end{tabular}

filtrates, concentrating the mixed filtrate to a moderate amount, adding ethanol to dissolve, move into a $5 \mathrm{~mL}$ volumetric flask, dilute with ethanol to volume, and mix, filter, take the subsequent filtrate $1.0 \mathrm{~mL}$, and pass take the subsequent filtrate through the $0.45 \mu \mathrm{m}$ Millipore filter as the TJF Granule sample solution.

Accurately absorbs $20 \mu \mathrm{L}$ TJF Granule sample solu- tion, inject into the high performance liquid chromatograph according to the chromatographic condition which above-mentioned and test, record the peak area of each chromatographic peak, each sample is paralleled tested twice, calculate the content according to the external standard dual point method and select the average. The result is shown in Table 6 and Figures 4-6. 
Table 6. Determination of stachydrine hydrochloride content of TJF granule.

\begin{tabular}{cc}
\hline Batch Number & $\begin{array}{c}\text { Stachydrine Hydrochloride Content } \\
\text { (mg/g Granule) }\end{array}$ \\
\hline 091201 & 0.785 \\
091202 & 0.796 \\
091203 & 0.825 \\
\hline
\end{tabular}

According to the determination results of Stachydrine hydrochloride for different batch number of TJF Granule, select the average number with a $20 \%$ decrease of the Stachydrine hydrochloride content in 3 batch numbers of TJF Granule, temporary define no less than $3.80 \mathrm{mg}$ Stachydrine hydrochloride should be tested for each bag of TJF Granule.

\subsection{Experimental Result of Stachydrine Hydrochloride in TJF granule}

RESULT: Good linearities of stachydrine hydrochloride and was obtained within the range of $0.20-1.98 \mu \mathrm{g} / \mathrm{mL}$ $(\mathrm{R}=0.9995$; the average recoveries were $97.01 \%$; RS were $0.19 \%$.

\section{Discussion and Conclusion}

DISCUSSION: Determination method of stachydrine hydrochloride: scanning result of stachydrine hydrochloride standard substance tested by the ultraviolet spectrophotometer displays the wavelength of maximum absorption is $201 \mathrm{~nm}$, which is less than the cut-off wavelength of most mobile phases like methanol. Hence the ultraviolet detector is not suitable for the test, while the

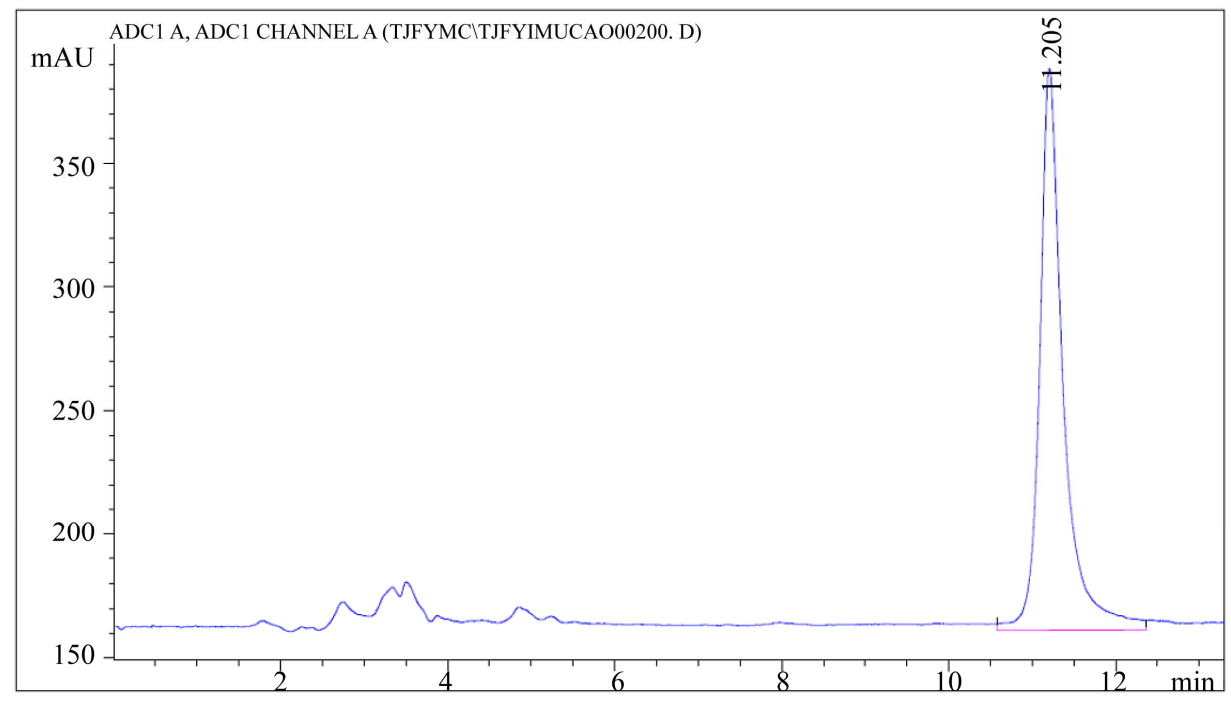

Figure 4. HPLC chromatogram of stachydrine hydrochloride standard substance.

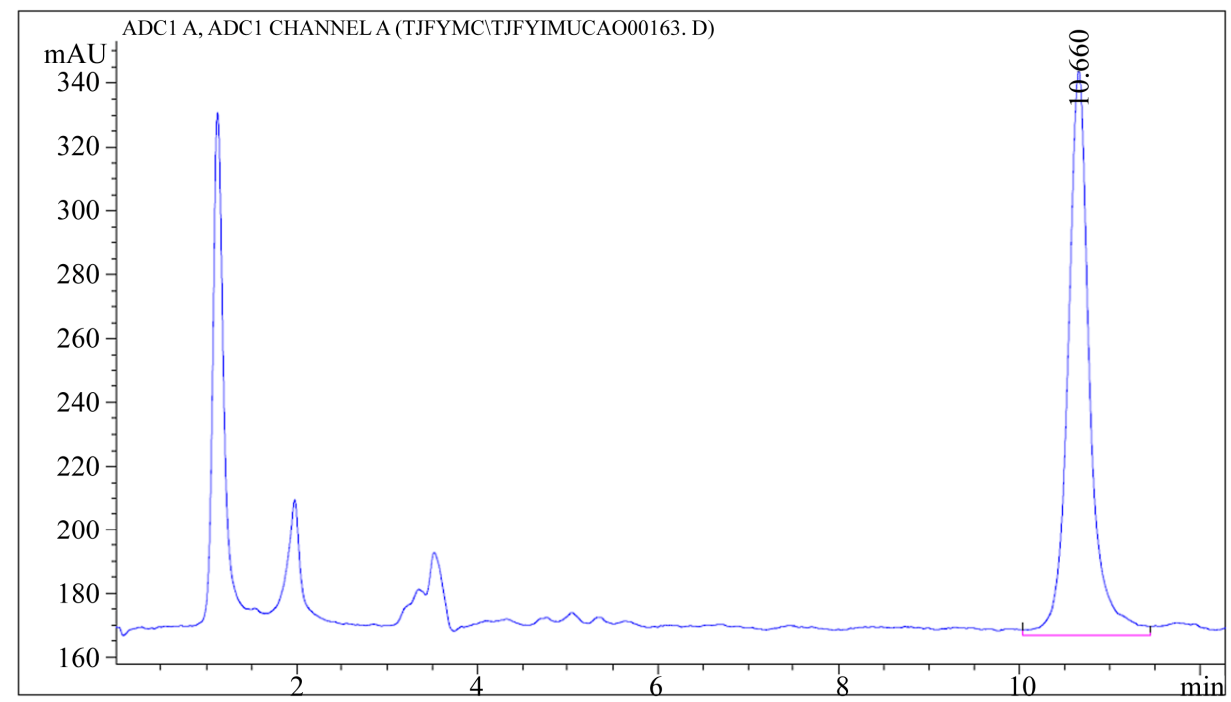

Figure 5. HPLC chromatogram of TJF granule sample. 


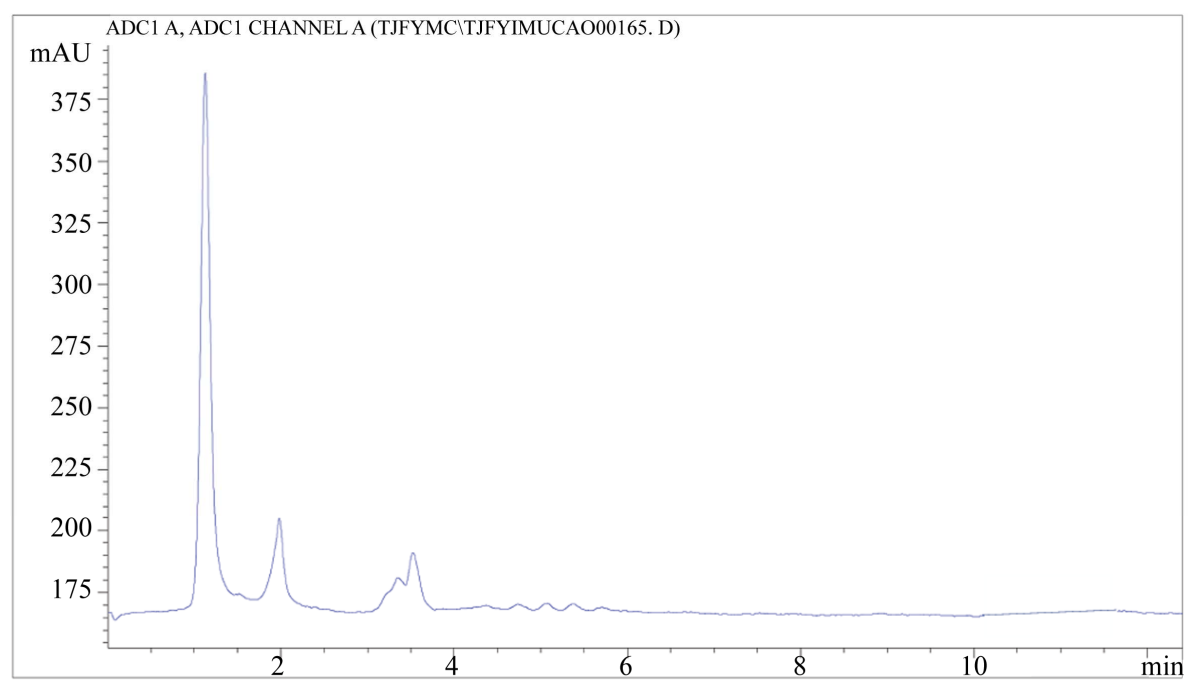

Figure 6. HPLC chromatogram of TJF granule negative reference substance.

evaporative light scattering detector (ELSD) should be adopted for determination.

In the first section of Chinese Pharmacopoeia 2005 Edition, determination method of Extractum Leonuri Liquidum is thin-layer chromatography scarmlng method (TLCS method). The ELSD-HPLC method is more convenient on operation and takes less time. Through the experiment, when the $\mathrm{C} 18$ reversed phase column is used on determination, chromatographic peak of Stachydrine hydrochloride has a severe zone tailing phenomenon, therefore, the $\mathrm{NH}_{2}$ column is adopted instead of the C18 reversed phase column.

The developing distance of Herba Leonuri Identification by TLC according to the first section of Chinese Pharmacopoeia 2005 Edition is not satisfied, the detection condition is not complete yet, and needs screening conditions continuously.

CONCLUSION: This method can be used for quality control of TJF granule.

\section{REFERENCES}

[1] China Pharmacopoeia Committee, "Section One," In: China Pharmacopoeia Committee, Ed., Chinese Pharmacopoeia 2005 English Edition, Chemical Industry Press (CIP), Beijing, 2005, pp. 203-205.

[2] Z. S. Huang, "Formula of Promoting Blood Circulation for Removing Blood Stasis," In: Z. S. Huang, Ed., Chinese Materia Medica, People's Medical Publication, Beijing, 2007, pp. 303-317.

[3] Z. Z. Tao, "Blood-Activating Formula," In: Z. Z. Tao, Ed., Chinese Materia Medica, People's Medical Publications,
Beijing, 2006, pp. 346-387.

[4] F. L. Yin, "Menstruation Disorder," In: F. L. Yin, Ed., Internal Medicine, Shanghai Science and Technology Publications, Shanghai, 2001, pp. 113-117.

[5] C. H, Zeng and W. H. Dai, "Emmeniopathy," In: C. H, Zeng and W. H. Dai, Eds., Internal Medicine, People's Medical Publications, Beijing, 2003, pp. 208-212.

[6] Y. H. Q. Ou, "Menstruation Diseases," In: Y. H. Q. Ou, Ed., Gynecology of Traditional Chinese Medicine, People's Medical Publications, Beijing, 2006, pp. 52-96.

[7] X. J. Chen, "Emmeniopathy," In: X. J. Chen, Ed., Internal Medicine of Traditional Chinese Medicine, Shanghai Science and Technology Publication, Shanghai, 2002, pp. 268-271.

[8] Y. K. Wang and F. C. Wang, "Menstruation Diseases," In: Y. K. Wang and F. C. Wang, Eds., Gynecology of Traditional Chinese Medicine, Chinese Press of Traditional Chinese Medicine, Beijing, 2009, pp. 31-78.

[9] Y. Z. Zhang, "Menstruation Disorder," In: Y. Z. Zhang, Ed., Traditional Chinese Gynecology, Chinese Press of Traditional Chinese Medicine, Beijing, 2005, pp. 25-63.

[10] X. M. Liang, Y. Wang and X. M. Zhang, "Determination of Stachydrine Hydrochloride in Herba Leonuri Granules by TLC," Chinese Traditional Patent Medicine, Vol. 7, No. 8, 2006, pp. 1073-10744.

[11] J. L. Ruan, "Research Developments of Herba Leonuri on the Chemical, Pharmacological and Clinical Researches," Journal of Chinese Herbal Medicine, Vol. 11, No. 6, 2003, pp. 15-19.

[12] X. Y. Meng and J. Q. Yang, "Research Developments of Herba Leonuri," Heilongjiang Medical Journal, Vol. 5, No. 1, 2007, pp. 467-468. 